\title{
OUTCOME OF ONE STAGE URETHROPLASTY USING BUCCAL MUCOSA FOR LONG SEGMENT URETHRAL STRICTURE
}

\author{
MD SIRAJUL ISLAM ${ }^{1}$, MD. FAISAL ISLAM ${ }^{2}$, ANAMUR RASHID CHOUDHURY², SARFORAJ ALI KHAN ${ }^{2}$, \\ PRANASHIS SAHA ${ }^{2}$
}

${ }^{1}$ Dept. of Urology, Jessore Medical College Hospital, ${ }^{2}$ Dept. of Urology, National Institute of Kidney Diseases \& Urology

\begin{abstract}
Objective: To assess the outcome of one stage urethroplasty using buccal mucosa for long segment (>2cm) urethral stricture.

Material \& Method: This retrospective study was done in a private Hospital at Jessore from May, 2010 to October, 2012. Twenty nine patients were managed with one stage dorsal on lay buccal mucosal graft (BMG). Patients were followed up 3 monthly with history, physical examination and relevant investigations. The mean duration of follow up was 23 months.

Result: The age of the patients ranged from 18 years to 65 years with mean of 35years. The length of the stricture ranged from $2.5 \mathrm{~cm}$ to $10 \mathrm{~cm}$ with mean length $5.5 \mathrm{~cm}$. The mean duration operative period was 3.5 hours with range from 2 hours to 4.5 hours. Of the 29 patients, 15 patients (51.7\%) had bulbar urethral stricture, 10 patients (34.5\%) had penile urethral stricture and 4 patients (13.8) had pan urethralstricture. Success was defined as normal voiding without further procedure. The rate of recurrence noted in this study was $10.34 \%$.
\end{abstract}

Conclusion: One stage dorsal on lay BMG urethroplsaty is a reliable and satisfactory procedure for the management of long segment urethral stricture with minimum complication.

Key words:BMG, BuccalMucossal Graft, BXO (BalanitisXeroticaObliterance).

Bangladesh J. Urol. 2015; 18(2): 68-73

\section{Introduction:}

Urethral stricture is the scar of the sub epithelial tissue of the corpus spongiosum that constrict the urethral lumen. Treatment of this fastidious disease is sometime very frustrating both for the patients and urologist, particularly so if the stricture segment is a long one. In the literature, over two hundred different types of repair have been mentioned indicating that it is a difficult surgery fraught with many complications and poor functional and cosmetic results[1]. There are two main principles of the urethroplasty, namely the anastomotic technique and the tissue transfer. The use of vascularized local penile and preputial skin has been the main stay of urethral reconstruction for a long time. Apart from theinadequate functional and cosmetic results there was the constraint of the supply of the genital tissue for long

Correspondence : Md. Sirajul Islam, Assistant Professor of Urology, Jessore Medical College Jessore, E-mail: sirajulislam1961 @yahoo.com segment of stricture. This constraint instigated the search for newer tissue source. Since 1909, wide variety of free graft of extra genital tissues includingfull and partial thickness of extra genital skin, ureter, tunicavaginalis, and bladder mucosa has been used.

For hundred years, oral mucosa had variously been utilized as free graft in plastic reconstructive surgery[2]. It is generally accepted that Humby[3], a plastic surgeon, first reported the use oral mucosa in urethroplasty in hypospadias repair in 1941; but literature review has revealed that Kirill Sapezhko, a Russian surgeon, first described it as early as in 1890 in a 40-year-old patient with idiopathic urethral stricture[4].But the current enthusiasm for this technique has been prompted in the last two decades of the past century by Duckett in 1986, Burger and associates in 1992[5], Dessanti and colleagues in 1992[6] and Elkasaby et al. in 1993[7]. Following this initial surge of rejuvenation of this technique, a good number of urologists around the world 
reported their success of using buccal mucosa in the treatment of urethral stricture and hypospadias repair in virgin and failed cases[8-15]. Nowadays, buccal mucosa remains the main armamentarium[16] for the treatment of urethral stricture offering the surgeon a considerable sense of confidence and comfort to treat the long segment stricture disease.

\section{Material and Methods}

This is a retrospective study conducted in a private hospital in Jessore. From May, 2010 to October, 2012.

Inclusion criteria was Stricture $>2 \mathrm{~cm}$ in length and Exclusion criteria were

i. Stricture with total obliteration of urethral lumen

ii. Stricture with extensive, active and aggressive lichen sclerosis.

According to inclusion and exclusion criteria 29 patients were included in the study.

Patients presenting with problems suggesting of urethral stricture were evaluated with history, physical examination, ultrasound examination of kidney, ureter, bladder and prostate along with MCC and PVR, imaging

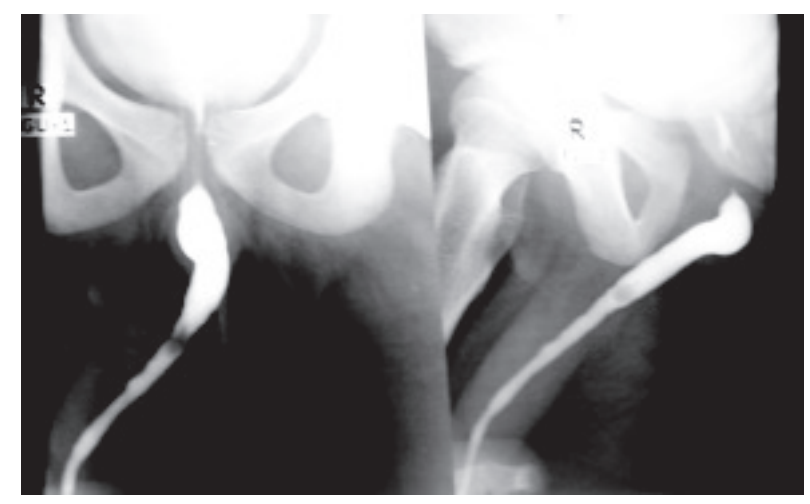

continued up to coronal sulcus. In these cases a dorsal meatotomy was done from above. The dissected urethra was rotated $90^{\circ}$ applying two stay sutures (Fig.-3) at its left lateral side. Dorsal urethrotomy incision was made on the stricture segment with an extension of one $\mathrm{cm}$ in the normal urethra in each side.

Inner aspect of the cheek was infiltrated with 1 in 200,000 adrenaline solution mixed with $1 \%$ lignocainefor minimizing per operative bleeding and post-operative pain. Buccal mucosa is harvested in the plane superficial to the buccinators muscle avoiding injury to the opening of the Stensen'sduct and the donor site was left open after properhaemostasis with bipolar cautery. Usuallya $6-\mathrm{cm}$ long graft is easily harvested from one side of the inner cheek. If the required graft length is more than 6 $\mathrm{cm}$, the incision is extended towards the lower lip. This way a graft length of up to $10-12 \mathrm{~cm}$ can easily be harvested. The graft is then defatted, fenestrated and tailored to its proper size (Fig.-4)

The harvested mucosa is splayed and quilted on the cavernous bed and its margin was sutured to that of urethrotomy with 5/0 vicryl over 16 Frcatheter (Fig.-5). Suprapubic catheter is not usually used unless there is

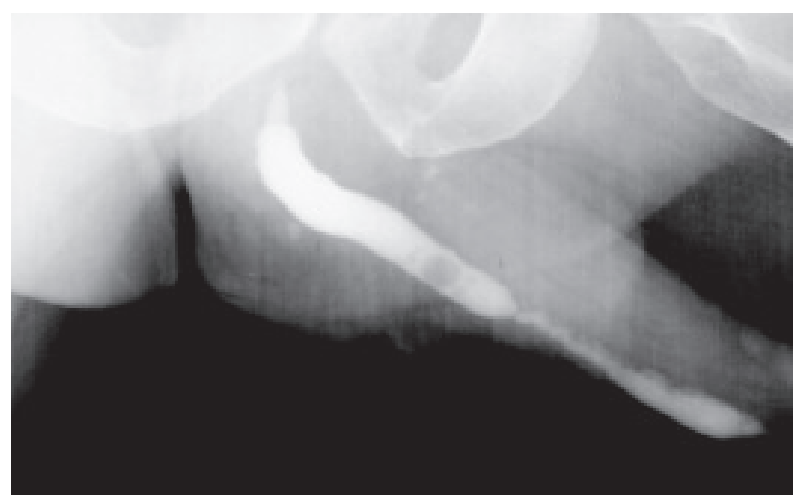

Fig.-1: RGU showing long segment urethral stricture.

study with retrograde urethrogram (RGU) and voiding cystourethrogram (VCUG) (Fig.-1), urofowmetry, urinalysis, urethroscopy before surgery, renal function tests and other relevant investigations.

Operation was performed under general anaesthesia with nasotracheal intubation and in exaggerated lithotomy position. Through midline perineal incision (Fig.-2) the corpus spongiosumwas approached after dividing the bulbospongiosum muscle in the midline and separating it from the corpus spongisum. The urethra was then dissected out from left side preserving vascularityand nervous innervations on the right side. In case of penile and pan urethral stricture penis was invaginated into the perineal wound and urethral dissection was

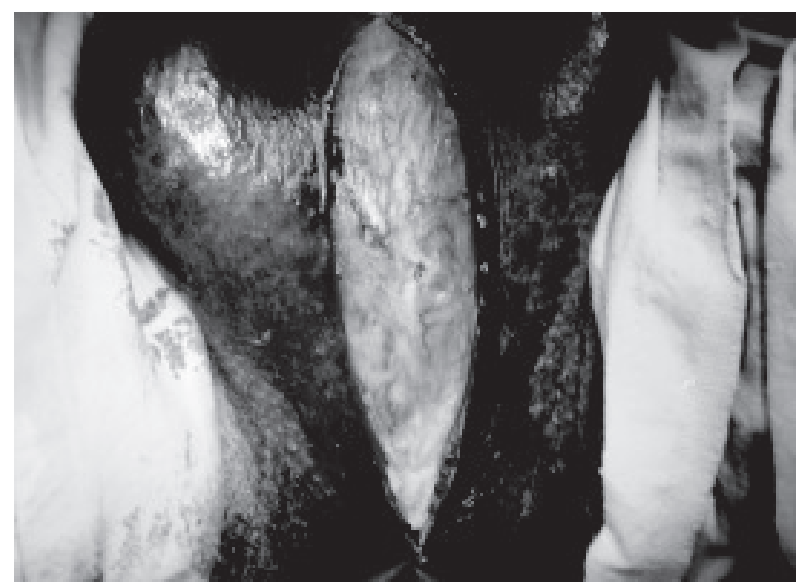

Fig.-2: Perineal midline incision. 


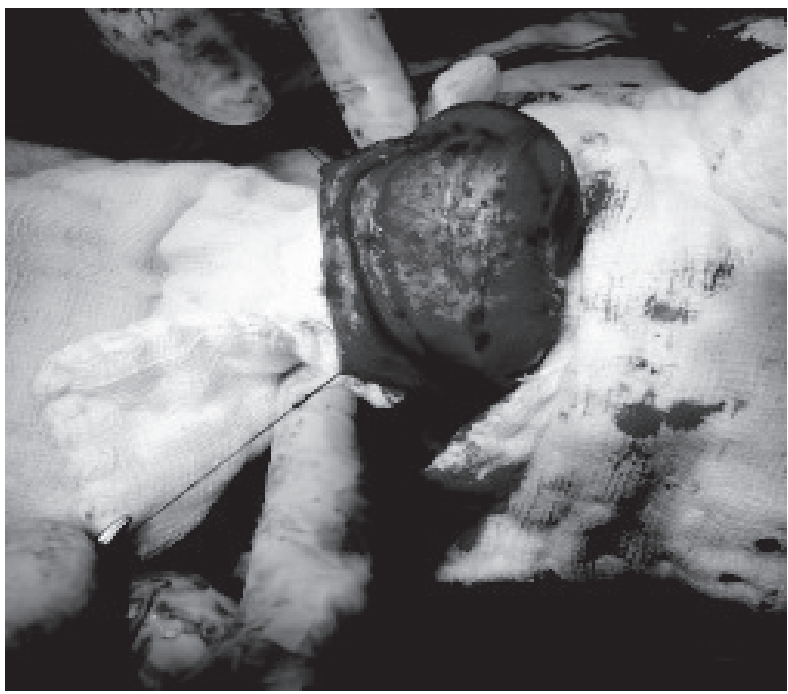

Fig.-3: Urethra dissected from left lateral side.

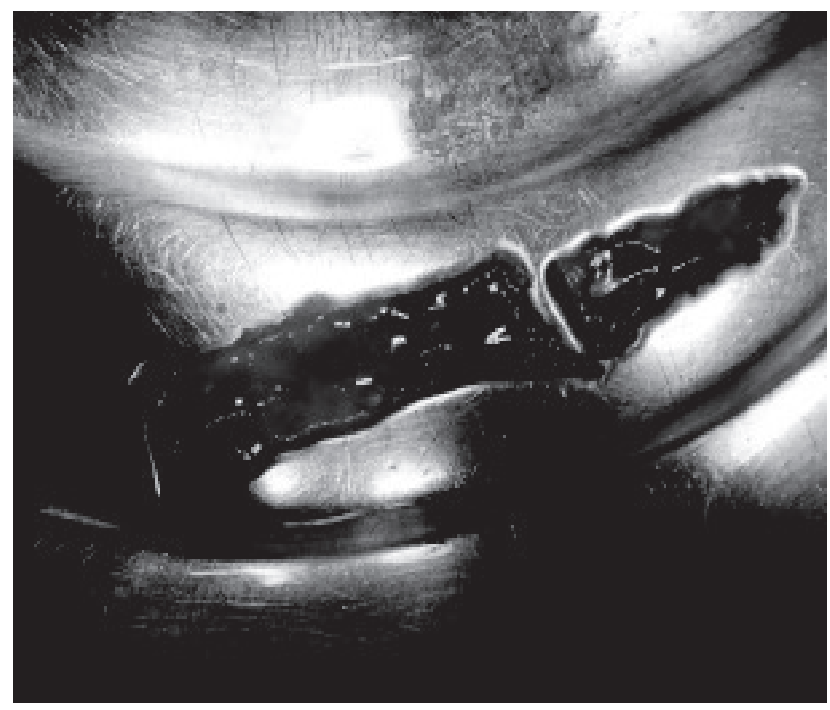

Fig.-4:Buccal mucosa after being defatted.
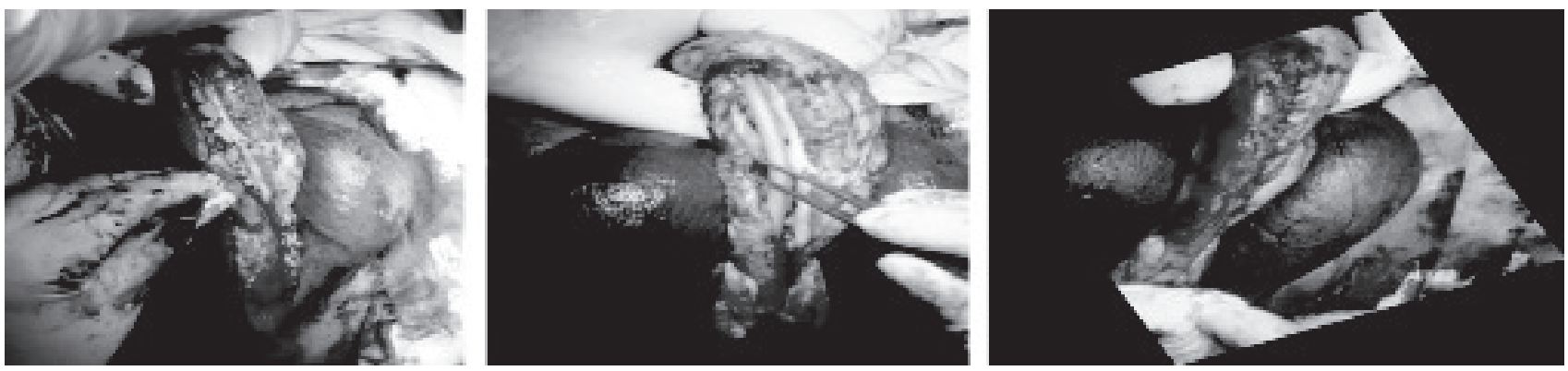

Fig.-5: Graft quilted on the bed and urethroplasty completed.

one already with the patient. All patients were operated by the same surgeon andall of them received perioperative antibiotic.

Pericatheterurethrogram was done after 3 weeks and catheter was removed if no leakage was detected. In case of leakage, catheter was left indwelling for further one week.

First follow up was done after three months with history regarding ease of voiding, local examinations, urinalysis, USG of KUB with PVR,RGU \&MCU and uroflowmetry. A successful outcome was defined as normal voiding without the need of any further procedure. Patients were further followed up 3 monthly with uroflowmetry and PVR. In cases suggesting recurrence RGU and $\mathrm{MCU}$ and urethrocystoscopy was done.

\section{Results}

A total of 29 patients underwent one stage BMG urethroplasty with dorsal on lay graft.Of the 29 patients, 15 patients $(51.7 \%)$ had stricture at the bulbar urethra, 10 patients $(34.5 \%)$ had stricture at the penile urethra and 4 patients (13.8) had pan urethralstricture. The age range of the patients was 18 to 65 years with a mean of 35 years. The length of the strictures varied from 2.5 to
$10 \mathrm{~cm}$ with a mean of $5.5 \mathrm{~cm}$. The duration of operation extended from 2 hours to 4.5 hours with a mean of 3.5 hours. The mean duration of follow up was 23 months ranging from 12 months to 36 months. Only two patients required per operative blood transfusion. The mean hospital stay was 5.5 days ranging from 4 to 8 days. From the aetiologicalpoint of view, out of 29 patients, 15 patients $(57.7 \%)$ had post inflammatory stricture, 10 patients (34.5\%) hadbalanitisxeroticaobliterans (BXO), 1 patient $(3.5 \%)$ had post traumatic stricture and 3 patients $(10.3 \%)$ had stricture of idiopathic nature.

Out of 29 patients, 3 patients (10.3\%) developed postoperative infection which was managed with proper dressing and administration of appropriate antibiotic. Two cases $(6.9 \%)$ having surgery on the penile urethra developed penile haematoma managed by aspiration and application of compression bandage. Five patients experienced temporary difficulty in mouth opening which resolved spontaneously with time. Pericatheter leakage, managed by extension of the period of catheterization for further oneweek was noted in 1 patient (3.5\%). Three patients $(10.34 \%)$ developed recurrencemanaged by optical internal urethrotomy followed by self-dilatation. 
Tablel-I

\begin{tabular}{lcc}
\hline Character & Range & Mean \\
\hline Age of the patient & 18 to 65 years & 35 years \\
Length of stricture & $2.5 \mathrm{~cm}$ to $10 \mathrm{~cm}$ & $5.5 \mathrm{~cm}$ \\
Duration of operative & 2 hours to 4.5 & 3.15 hours \\
& hours period & \\
\hline
\end{tabular}

Table II

Site of strictures

\begin{tabular}{lcc}
\hline Site of stricture & Number & Percentage \\
\hline Bulbar & 15 & $51.7 \%$ \\
Penile & 10 & $34.5 \%$ \\
Pan urethral & 04 & $13.8 \%$ \\
\hline
\end{tabular}

Table III

Aetiology of the strictures

\begin{tabular}{lcc}
\hline Type & Number & Percentage \\
\hline Post inflammatory & 15 & $51.7 \%$ \\
BXO & 10 & $34.5 \%$ \\
Traumatic & 01 & $3.5 \%$ \\
Idiopathic & 03 & $10.3 \%$ \\
\hline
\end{tabular}

Table IV

Complications

\begin{tabular}{lcc}
\hline Type of complication & Number & Percentage \\
\hline Infection & 03 & $10.3 \%$ \\
Penile haematoma & 02 & $6.9 \%$ \\
Transient limitation of & 05 & $17.2 \%$ \\
mouth opening & & \\
Pericatheter leakage & 01 & $3.5 \%$ \\
Recurrence & 03 & $10.34 \%$ \\
\hline
\end{tabular}

Table V

Comparison of pre-operative and post-operative functional outcome.

\begin{tabular}{|c|c|c|c|c|c|}
\hline \multirow[t]{2}{*}{ Character } & \multicolumn{2}{|c|}{ Pre-operative } & \multicolumn{2}{|c|}{ Post-operative } & \multirow[t]{2}{*}{ P-value } \\
\hline & Range & Mean & Range & Mean & \\
\hline Post void residue & $50 \mathrm{ml}$ to $215 \mathrm{ml}$ & $75 \mathrm{ml}$ & $10 \mathrm{ml}$ to $30 \mathrm{ml}$ & $20 \mathrm{ml}$ & $<0.01$ \\
\hline Q-max & $6 \mathrm{ml}$ to $17 \mathrm{ml}$ & $9.5 \mathrm{ml}$ & $17 \mathrm{ml}$ to $24 \mathrm{ml}$ & $19.5 \mathrm{ml}$ & $<0.01$ \\
\hline
\end{tabular}

\section{Discussion}

There are multiple factors including patient's age, surgical technique, graft material,aetiology, length and site of stricturewhich influence the outcome of BMG urethroplasty. The survival of graft depends on the well vascularized bed. With increasing age the vascularity of tissue become less in many patients due to the atherosclerotic narrowing of blood vessels. So the graft survival in aged patients may be inferior compared to that in young ones[17]. Of the three patients having recurrence in the current series, one was 60 plus and rest two were below 40 years of age. So the impact of age on the outcome of BMG urethroplasty could not assessed for sure with this small number of patients of the present series. Length, site and aetiology of the stricture have been reported to have impact on the outcome of the procedure ${ }^{18}$. Stricture involving penile urethra has greater failure rate than that involving the bulbar urethra which is more ideal as graft bed owing its rich vascularity[19]. Two of the three cases of recurrence in this series had stricture having bulbopenile involvement. The extent of spongiofibrosis plays important role to predict the outcome BMG urethroplasty as it compromises the vascularity of the graft bed. Spongiofibrosis more extensive in $\mathrm{BXO}$ and ischaemic stricture resulting from prolonged catheterization. The recurrence rate is more in these cases[20]. Two out of three cases of recurrence in this series had the aetiology of BXO and pan urethral involvement. Some authors suggest two stage urethroplasty for these cases considering the worse predictor significance of these aetiology[21]. The underlying cause responsible for recurrence of stricture in $\mathrm{BXO}$ might be the graft failure or progression of the primary diseasethe former gives early recurrence and the latter gives late recurrence. Presence of haematoma and infection might also contribute to the graft failure giving rise to early recurrence[18].

The choice of approach to the urethral lumen varies among the surgeons. The dorsal on lay procedure is acclaimed to have some advantage over the ventral on lay graft urethroplasty[22]. In the dorsal on lay method 
the graft is fixed to the under surface of coporal bodies which has excellent blood supply and mechanical support[23]. The tensile strength of corporal bodies reduces the chance of graft shrinkage and chordee formation. As the graft is interposed between the urethra and corporal bodies, chance of sacculation is eliminated and incidence of fistula formation is limited[22]. In the present series dorsal on lay procedure has been followed considering its many upsides. Though dorsal on lay procedure has many points to be the method of choice, Barbagli et al. found equal rate of stricture recurrence in a study with graft placed on the ventral, dorsal and lateral sides of bulbar urethra in a nonrandomized retrospective study[24].

When buccal mucosa was first introduced as graft material for urethroplasty the inner cheek and the lower lip were chosen as the donor site. Later the under surface of the tongue has been included as potential donor site by few surgeons[25-28]. During harvest from inner cheek care should be taken not to make injury to Stensen duct and during harvest from lip surgeon should be away from the angle of mouth to avoid permanent deformity[29]. In the present series for long graft harvest incision was extended from the cheek on to the lower lip. The temporary difficulty in mouth opening during the immediate postoperative period subsided spontaneously leaving no permanent deformity but persistent perioral numbness, salivatory changes and difficulty in mouth opening have been reported by some authors[30]. In the present series the donor site was left unsutured and no post-operative bleeding was encountered. The advantage of the no closure of the donor site has been reported to have been associated with less postoperative pain[30]. The lingual mucosa is an alternative source when the cheek mucosa and labial mucosa is exhausted but its harvest has been reported to have resulted in more bleeding[28] and salivatory change.

In the preset series the success rate is $89.64 \%$. Barbagli et al. reported success rate $80.4 \%$ and Levine et alreported success rate $81.4 \%$ while Elliot et al. reported $90 \%$ success rate[24]. The higher success in the present series might be due to shorter follow up period. The recurrence of urethral stricture has been reported as late as 15 years after urethroplasty[28]. Two of the three cases of failure have the aetiology of BXO. The recurrence was noted late indicating progression of the disease process rather than graft failure as the cause responsible for recurrence. In this series the recurrence rate in $\mathrm{BXO}$ cases is $20 \%$ as opposed to the overall recurrence of $10.34 \%$. So the outcome of BMG urethroplasty is worse in stricture having the aetiology of BXO than those having other aetiology. The inferior outcome of urethroplasty in BXO has also been suggested by Levin LA et al.[20]

The limitation of the study is shorter follow up period, nonhomogenous nature of cases in term of the aetiology, site and length of the stricture and age of the patients.

\section{Conclusion}

Despite the uniqueness of buccal mucosa as graft material for substitution urethroplasty, single stage BMG urethroplasty has variable failure rate. Extended follow up is needed on homogenous group of patients to indentify the role of specific factor on the outcome of single stage BMG urethroplasty and search should be continued to contrive newer surgical technique and find out further better substitution material.

Conflict of Interest : None declared.

\section{References}

1. Duckett JW. Transverse preputial island flap technique for repair of severe hypospadias. Urol Clin North Am. 1980;7:423-430.

2. Filipas D, Wahlmann $U$, Hohenfellner R. History oral mucosa. Eur Urol. 1998;34:165-168.

3. Humby G, Higgins TT. A stage operation for hypospadias .british Journal of Surgery. 1941;29: 84-92.

4. Korneyevl, llyin D, Sculthesiss D, Chapple C. The oral mucosal graft was carried out in the $19^{\text {th }}$ century: The pioneering experience of Kirill Sapezhko. Eropean Urology.2012;62:624-627.

5. Burger RA, Muller SC, el-Demanhoury $H$, Tschakaloff A, Riedmiller H, Hoenfellner R. Thebuccal mucosal graft for urethral reconstruction: a preliminary report. J Urol.1992;147:662664.

6. Dessanti A, Rigamonti W, Merulla V, Falchetti D, Caccia G. Autologous buccal mucosal graft for hypospadias repair: an initial report. J Urol. 1992; 147: 1081-1083.

7. el -Kasaby AW, Fath- Allah M, Nowweir AM, elHalaby MR,el-Beialy MH. The use of oral mucosal patch graft in the management anterior urethral strictures. J Urol.1993;149:276.

8. Ransley PG, Manzoni GM. Buccal mucosal graft for hypospadias. In:Ehrlich RE, Alter GJ, editors. 
Reconstructive and Plastic Surgery of external genitalia, Adult and Paediatric. Philadelphia, PA: WB Saunders company;1999.p.121.

9. Bhargava S, Chapple CR. Buccal mucosal urethroplasty: Is it the new gold standard? BJU Int. 2004; 93:1191-1193.

10. Fabbroni G, Loukota RA, Eardley I. Buccal mucosal graft for urethroplasty:Sugical technique and morbidity. Br J Oral Maxillofac Surg.2005;43: 320-323.

11. Palminteri E, Manzoni G, Bernondini $E$ et al. Combined dorsal plus ventral double buccal mucosal graft in bulbar urethral reconstruction. Eur Urol. 2008;53:81-89.

12. Elgamal $S$, Ragab MM, Farahat $\mathrm{Y}$, Elnady $\mathrm{M}$, Elsharaby M, Abo Farah O. A prospective randomized study coparingbuccal lingual mucosal dorsal on lay graft for the management of anterior urethral strictures. Tantana Medical Journal. 2008;36:597-608.

13. Hu X, Xu Y, Song L,Zhang H. Combined buccal and lingual mucosal grafts for urethroplasty: An experimental study in dogs. J Surg Res.2009.

14. Kumar A, Das SK, Trevedi S, DwivediUS, Sing PB. Substititionalurethroplasty for anterior urethral stricture :Buccal versus lingual mucosal graft.Urol Int.2010;84:78-84.

15. Sing O, Gupta SS, Arvind NK. Anterior urethral strictures: A brief review of the current surgical treatment. Urol Int.2011;86:1-10.

16. Bhargava S, Chapple CR. Buccal mucosal urethroplasty: Is it the new gold standard? BJU Int.2004; 93:1191-1193.

17. Mehrsai A, Djaladat $H$, Salem $S$, Jahagiri $R$, Pourmand G. Outcome of buccal mucosal urethroplasty for long and repeated stricture repair. Urology 2007;69:17-21.

18. Hosseini J, Kaviani A, Hosseini M, Mazloomfard MM, Razi A. Dorsal versus ventral oral mucosal graft urethroplasty. Urology Journal 2011;8(1): 48-53.

19. Wessells $H$, McAninch JW. Use of free graft in urethral stricture reconstruction. The Joural of Urology1996; 155:1912-1915.

20. Levine LA, Strom KH, Lux MM. Buccal mucosa graft urethraplasty for anterior urethral stricture repair: Evaluation of the impact of stricture location and lichen scloresus on surgical outcome. J Uol 2007;178:2011-2015.

21. Arlen AM, Powell CR, Hoffman HT, Kreder KJ. Buccal mucosal graft urethroplasty in the treatment of urethral stricture: Experience using the two surgeon technique. The scientific world journal 2010;10:74-79.

22. Wright EJ, Webster GD. Dorsal graft repair urethral stricture. AUA News 1996; 1(4): 12.

23. Barbagli G, Selli C, Tosta A, Palminteri E. Dorsal free graft urethroplasty. J Urol 1996;155:1233.

24. Barbagli G, Palmineri E, Gauzzoni G, Montorsi F, Turini D, Lazzeri M. Bulbar urethroplasty using buccal mucosal grafts placed on the ventral, dorsal or lateral surface of the urethra: are results affected by the surgical technique? The journal urology 2005; 174:955-958.

25. Das SK, Kumar A, Sharma AK, Pandey AK, BansalH,Trvedi S, Dwivedi US, Bhattacharya V, Sing PB. Lingual mucosal graft urethroplasty for anterior urethral strictures. Urology 2009:73:105108.

26. Simonato A, Gregori A, Lissiana A, Galli S, Ottaviani F, Rossi R, Zappone A, CarmignaniG. The tongue as an alternative donor site for graft urethroplasty: A pilot study. The Journal Urology 2006;175: 589-592.

27. Simonato A, Gregori A, Ambrusi C, Venzano F, Varca V, Romagnoli A, Carmignani G. Lingual mucosal graft urethroplasty for anterior urethral reconstruction. European Urology 2008;54:79-87.

28. Barbagli G, Angelis MD, Romano G, Ciabbati PG, Lazzeri $M$. The use of lingual mucosal graft in adult anterior urethroplasty: Surgical steps and shortterm outcome. European urology 2008;54:671-676.

29. Ragab M, Haroun H. Oral mucosa graft: An ideal substitute for urethroplasty.www. intechopen.com.

30. Wood DN, Allen AC, Andrich DE, Greenwell TG, Mundy AR. The morbidly of the buccal mucosal graft harvest for urethroplasty and the effect of nonclosure of the graft harvest site on post operative pain. The Journal of Urology 2004;172:580-583.

Abbreviations:

BMG : Buccal mucosal graft

BXO : Balanitis Xerotica Obliterans

MCU : Micturating cystourethrogram

RGU : Retrograde cystourethrogram. 